\title{
High Resolution and Solid State NMR Investigations of Subvalent Gallium Compounds*
}

\author{
Hubert Schmidbaur. Theodore Zafiropoulos, Wolfgang Bublak, Paul Burkert. \\ and Frank H. Köhler \\ Anorganisch-chemisches Institut der Technischen Universität München, Garching
}

Z. Naturforsch. 41 a, 315-318 (1986); received July 22, 1985

\begin{abstract}
The ${ }^{71} \mathrm{Ga}$ NMR spectra of $\mathrm{Ga}\left[\mathrm{GaX}_{4}\right]$ melts and of solutions in benzene and other hydrocarbons show discrete sharp $\mathrm{Ga}^{\mathrm{I}}$ and broad $\mathrm{Ga}^{\mathrm{III}}$ resonances. In the light of recent structure determinations, the solution $\mathrm{Ga}^{\mathrm{I}}$ signals must be attributed to bis(arene) $\mathrm{Ga}^{+}$complexes in which the gallium atom is $\eta^{6}$-bonded to the hydrocarbons. The low line widths and strong high field shifts are attributed to an almost spherical shielding of the metal nucleus by the $4 \mathrm{~s}^{2}$ electrons. Solid state ${ }^{69} \mathrm{Ga}$ and ${ }^{71} \mathrm{Ga}$ NMR spectra of $\mathrm{Ga}\left[\mathrm{GaCl}_{4}\right]$ crystalline powder show only $\mathrm{Ga}^{1}$ resonances. While the ${ }^{71} \mathrm{Ga}^{1}$ line is rather narrow, the ${ }^{69} \mathrm{Ga}^{1}$ line has a complex fine structure. Consistent with the crystal structure of $\mathrm{Ga}\left[\mathrm{GaCl}_{4}\right]$, the $\mathrm{Ga}^{\mathrm{I}}$ ion is calculated to have a very low quadrupole coupling constant $e^{2} q Q / h=1.7 \pm 0.1 \mathrm{MHz}$ and an asymmetry parameter $\eta=0.44$. Experimental and simulated line shapes (using literature models) are in satisfactory agreement, implying that the ${ }^{69} \mathrm{Ga}$ signal splitting is due to second order quadrupolar effects for the central $m=+1 / 2 \leftrightharpoons-1 / 2$ transition. The analogous splitting of the ${ }^{71} \mathrm{Ga}$ NMR line is too small to be detected.
\end{abstract}

\section{Introduction}

Subvalent gallium compounds with the metal in the non-classical oxidation states +1 or +2 have attracted considerable attention ever since their discovery in the first decades of this century [1]. Many physical methods have been used to elucidate various features of structure, bonding, and reactivity, but it was not until 1965 that NMR spectroscopy could be employed for these purposes [2, 3]. Very recently it appears that ${ }^{71} \mathrm{Ga}$ NMR could become almost a routine technique in studies of reaction mechanisms and products $[4,5]$.

In the course of our own investigations on novel arene complexes of gallium and its homologues [1, $5-10]$ it was also necessary to reconsider the structures of the arene-free $\mathrm{Ga}\left[\mathrm{GaX}_{4}\right]$ species. The original X-ray structure determination of the chloride, $\mathrm{Ga}\left[\mathrm{GaCl}_{4}\right]$, was not very accurate on modern standards [11]. Interestingly enough, a recent study of

* Presented at the VIIIth International Symposium on Nuclear Quadrupole Resonance Spectroscopy, Darmstadt, July $22-26,1985$.

Reprint requests to Prof. $\mathrm{H}$. Schmidbaur, Anorganischchemisches Institut der TU München, Lichtenbergstraße 4, 8046 Garching.
$\operatorname{In}\left[\operatorname{InI}_{4}\right]$ confirmed the structural concept of the $\mathrm{Ga} / \mathrm{Cl}$ analogue [12], while the compound $\mathrm{Ga}\left[\mathrm{GaI}_{4}\right]$ was shown to have an entirely different structure [13].

In order to contribute to the questions of the environmental symmetry of the gallium(I) cations in the crystal, in the melt, and in non-aqueous solutions, Ga NMR spectroscopy was used for studies of $\mathrm{Ga}\left[\mathrm{GaCl}_{4}\right]$ in all three phases. $\mathrm{Ga}\left[\mathrm{GaBr}_{4}\right]$ was included into the solution studies.

\section{Experimental}

Samples: $\mathrm{Ga}\left[\mathrm{GaCl}_{4}\right]$ and $\mathrm{Ga}\left[\mathrm{GaBr}_{4}\right]$ were prepared according to literature methods [1] and their identity checked by melting points and analytical data. Solutions were obtained from high purity aromatic hydrocarbons, which were dried and saturated with nitrogen.

Spectra: For both the solid state and the solution measurements a Bruker CXP 200 was used.

For the ${ }^{69} \mathrm{Ga}$ powder pattern the Larmor frequency was set at $v_{\mathrm{L}}=47.989 \mathrm{MHz}$, for ${ }^{71} \mathrm{Ga}$ at $v_{\mathrm{L}}=60.790 \mathrm{MHz}$. A pulse width of $4 \mu \mathrm{s}$ was used $(\mathrm{DL}=50 \mathrm{~ms}$, NS $=2000, F= \pm 200 \mathrm{~Hz}) . \mathrm{HCl}$-acidic aqueous $\mathrm{GaCl}_{3}$ solutions served as reference $(\delta=0 \mathrm{ppm})$.

0340-4811/86/0100-0315\$01.30/0. - Please order a reprint rather than making your own copy. 
For the ${ }^{71} \mathrm{Ga}$ solution spectra the spectrometer frequency $v=60.990 \mathrm{MHz}$ was employed. $\mathrm{HNO}_{3}$ acidic aqueous $\mathrm{Ga}\left(\mathrm{NO}_{3}\right)_{3}$ served as an external standard.

For the calculations of the spectrum shown in Fig. 3 the literature procedure was followed [14].

\section{Results}

\section{I. ${ }^{71} \mathrm{Ga}$ and ${ }^{69} \mathrm{Ga}$ NMR Studies of Polycrystalline $\mathrm{Ga}\left[\mathrm{GaCl}_{4}\right]$}

The ${ }^{69} \mathrm{Ga}$ NMR spectrum of gallium(I) tetrachlorogallate(III) as measured at $303 \mathrm{~K}$ exhibits a resonance with a complex fine structure as shown in Figure 1. The central line appears at $\delta=-844 \mathrm{ppm}$ rel. to the aqueous $\mathrm{Ga}^{3+}$ standard. The ${ }^{71} \mathrm{Ga}$ NMR spectrum consists of only one, relatively sharp resonance (Fig. 2) with the same chemical shift.

Considering the relations $Q\left({ }^{69} \mathrm{Ga}\right)>Q\left({ }^{71} \mathrm{Ga}\right)$ and $\mu\left({ }^{69} \mathrm{Ga}\right)<\mu\left({ }^{71} \mathrm{Ga}\right)[14]$, it follows that the fine structure of the ${ }^{69} \mathrm{Ga}$ signal is not due to shift anisotropy effects, but originates from second order quadrupole effects associated with the central $m= \pm 1 / 2 \leftrightharpoons-1 / 2$ transition. According to theoretical calculations, using asymmetry parameters $\eta>1 / 3$, these effects lead to signal shapes as shown in Figure 3. The agreement with the experi-

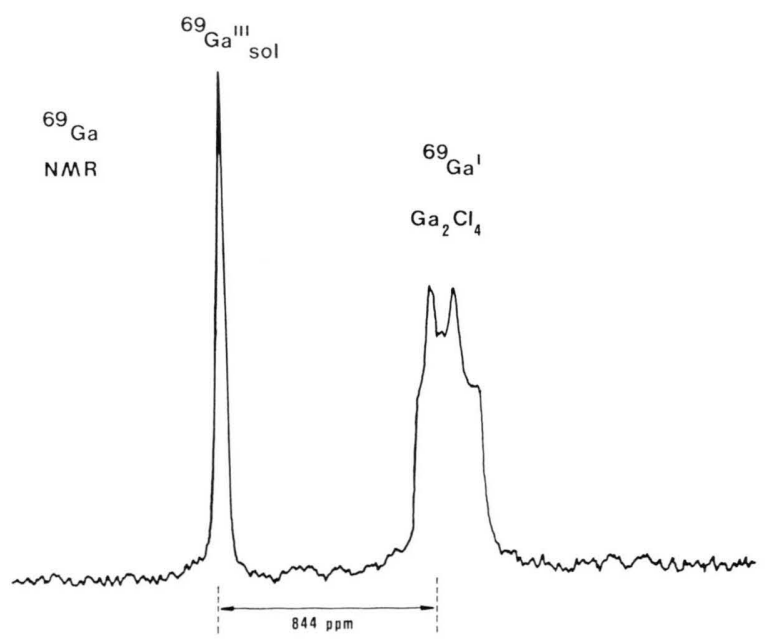

Fig. $1 .{ }^{69} \mathrm{Ga}$ spectrum of $\mathrm{Ga}\left[\mathrm{GaCl}_{4}\right]$ powder at $303 \mathrm{~K}$. Reference: $\mathrm{HCl} / \mathrm{GaCl}_{3} / \mathrm{H}_{2} \mathrm{O}$ solution. $v_{\mathrm{L}}=47.989 \mathrm{MHz}$, sweep width $180 \mathrm{kHz}$, pulse $4 \mu \mathrm{s}, \mathrm{DL}=50 \mathrm{~ms}$, NS $=2000$; $F= \pm 200 \mathrm{~Hz}$ (see Fig. 3 for the calculated spectrum).

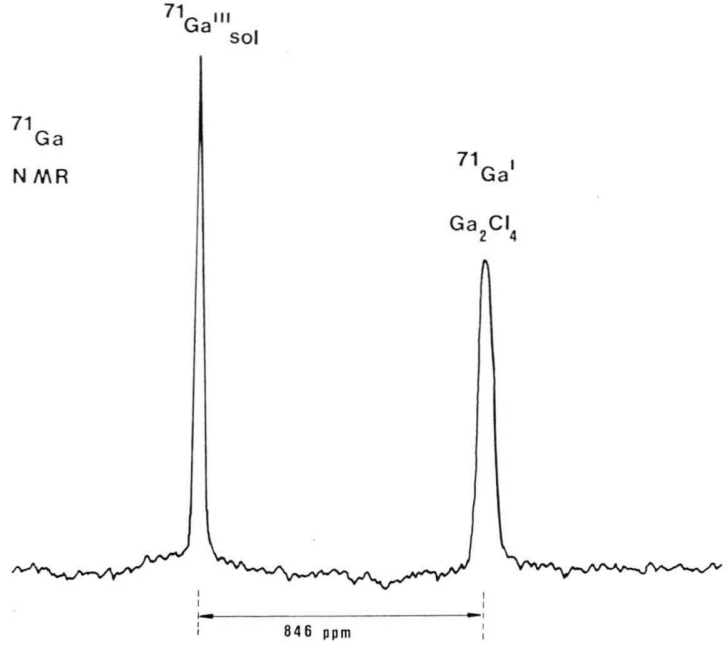

Fig. 2. ${ }^{71} \mathrm{Ga}$ NMR spectrum of $\mathrm{Ga}\left[\mathrm{GaCl}_{4}\right]$ powder at $303 \mathrm{~K} . v_{\mathrm{L}}=60.790 \mathrm{MHz}$. For other experimental settings see Figure 1.

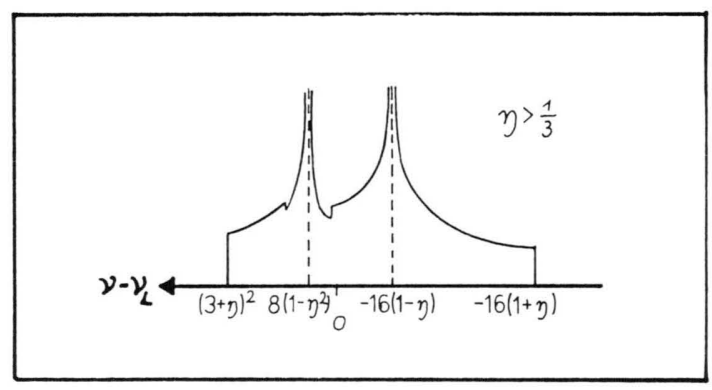

Fig. 3. Calculated line shapes for the central transition $(m=+1 / 2 \leftrightharpoons-1 / 2)$ of half integral nuclear spin $I$. Frequency units:

$$
\frac{v_{\mathrm{Q}}^{2}}{144 v_{\mathrm{L}}}\left[I(I+1)-\frac{3}{4}\right], \text { where } v_{\mathrm{Q}}=\frac{3 e^{2} q Q}{2 I(2 I-1) h} .
$$

(See Fig. 1 for the experimental spectrum.)

mental spectrum is quite satisfactory for values $e^{2} q Q / h\left({ }^{69} \mathrm{Ga}\right)=1.7 \pm 0.1 \mathrm{MHz}$ and $\eta=0.44 \pm 0.05$ (see Experimental Part).

For the corresponding ${ }^{71} \mathrm{Ga}$ quadrupole coupling constant a value $e^{2} q Q / h\left({ }^{71} \mathrm{Ga}\right)=1.1 \pm 0.1 \mathrm{MHz}$ is obtained from the above data. This value should give rise to a maximum splitting of the main frequency edges of $\Delta v=1500 \mathrm{~Hz}$, well below the experimental line width of $\Delta B=3070 \mathrm{~Hz}$ for the ${ }^{71} \mathrm{Ga}$ NMR resonance. Quadrupolar splittings are therefore not to be expected in this ${ }^{71} \mathrm{Ga}$ NMR experiment. 
The observed ${ }^{69} \mathrm{Ga},{ }^{71} \mathrm{Ga}$ NMR signals are assigned to the $\mathrm{Ga}^{\mathrm{I}}$ ions present in the $\mathrm{Ga}\left[\mathrm{GaCl}_{4}\right]$ sample. The severe distortion of the tetrahedral chlorine environment of the $\mathrm{Ga}^{\mathrm{III}}$ centers [11] is probably responsible for the absence of Ga ${ }^{\text {III }}$ NMR resonances. For the quadrupole coupling constants of the $\mathrm{Ga}^{\mathrm{III}}$ nuclei the condition $e^{2} \mathrm{q} \mathrm{Q} / \mathrm{h}\left(\mathrm{Ga}^{\mathrm{III}}\right)$ $\ll \mu B / h$ is not valid, and their effects exceed the experimental limit of this study.

The low quadrupole coupling constants determined for ${ }^{69} \mathrm{Ga}^{1}$ and ${ }^{71} \mathrm{Ga}^{1}$ in crystalline $\mathrm{Ga}\left[\mathrm{GaCl}_{4}\right]$ indicate that the dodecahedral coordination sphere of the univalent ions is distorted only slightly from the maximum $D_{2 \mathrm{~d}}$ symmetry. The orthorhombic space group is in agreement with this result [11]. The value for $\eta=0.44$ also shows that the symmetry of the electrical field gradient tensor at the $\mathrm{Ga}^{\mathrm{I}}$ cation is reduced according to the orthorhombic crystal symmetry.

As compared to $\mathrm{Ga}^{\mathrm{III}}$ species, these effects are relatively small. Clearly, the presence of a $4 \mathrm{~s}^{2}$ lone pair of electrons at $\mathrm{Ga}^{\mathrm{I}}$ leads to a high and symmetrical shielding of the gallium nuclei.

\section{II. ${ }^{71} \mathrm{Ga}$ NMR Spectrum of Molten $\mathrm{Ga}\left[\mathrm{GaCl}_{4}\right]$.}

The ${ }^{71} \mathrm{Ga}$ NMR spectrum of molten $\mathrm{Ga}\left[\mathrm{GaCl}_{4}\right]$ (at $200^{\circ} \mathrm{C}$ ) has already been reported by Greenwood and his collaborators [2]. Two resonances were found, which were assigned to $\mathrm{Ga}^{\mathrm{I}}$ and $\mathrm{Ga}{ }^{\mathrm{III}}$, respectively. The $\mathrm{Ga}^{\mathrm{I}}$ signal was surprisingly narrow, while the $\mathrm{GaX}_{4}^{-}$line showed the usual broadening typical of many gallium resonances.

Table 1. ${ }^{71} \mathrm{Ga}$ NMR spectrum of solutions of $\mathrm{Ga}\left[\mathrm{GaX}_{4}\right]$ in aromatic hydrocarbons. $v=60.990 \mathrm{MHz}$. Standard: $\mathrm{HNO}_{3}$ acidic aqueous $\mathrm{Ga}\left(\mathrm{NO}_{3}\right)_{3}$ (capillary). Line widths are $50 \mathrm{~Hz}$ at $400 \mathrm{~K}$ and $100 \mathrm{~Hz}$ at $300 \mathrm{~K}$ for gallium(I), but 1700 or $4700 \mathrm{~Hz}$ for gallium(III) (see Figure 4).

\begin{tabular}{lllll}
\hline & Solvent & $\begin{array}{l}\text { Conc. } \\
{[\% \mathrm{w} / \mathrm{w}]}\end{array}$ & $\begin{array}{l}\delta \mathrm{Ga}^{+} \\
{[\mathrm{ppm}]}\end{array}$ & $\begin{array}{l}\delta \mathrm{Ga}^{+++} \\
{[\mathrm{ppm}]}\end{array}$ \\
\hline $\mathrm{Ga}\left(\mathrm{GaCl}_{4}\right)$ & Benzene & 1 & -650 & +247 \\
& Benzene & 3 & -669 & +247 \\
& Toluene & 1 & -668 & +247 \\
& Toluene & 4 & -673 & +247 \\
& p-Xylene & 7 & -674 & +247 \\
& Mesitylene & sat. & -675 & broad \\
& Mesitylene/ & & & \\
& Benzene & sat. & -675 & +247 \\
$\mathrm{Ga}\left(\mathrm{GaBr}_{4}\right)$ & Benzene & 3 & -644 & +62 \\
& Mesitylene & sat. & -624 & broad \\
\hline
\end{tabular}

These results could be confirmed in more recent experiments employing modern equipment. There are similarities between the spectra of aromatic hydrocarbon solutions and the spectrum of the melt, especially regarding the chemical shifts and line widths of the $\mathrm{GaX}_{4}^{-}$resonances. This result suggests not only that assignments are correct, but also that the anionic parts of the samples are strongly coordinated to the $\mathrm{Ga}^{\mathrm{l}}$ centers thus rendering the $\mathrm{GaX}_{4}$ tetrahedra strongly distorted. The environment of the $\mathrm{Ga}^{\mathrm{I}}$ centers appears to be of only slightly reduced symmetry as judged from the low line widths of the ${ }^{71} \mathrm{Ga}^{1}$ signals. A quasi-dodecahedral halogen cage seems to be an acceptable model for the coordination array around $\mathrm{Ga}^{\mathrm{I}}$ in the melt.

\section{III. ${ }^{71} \mathrm{Ga}$ NMR Spectra of Solutions of $\mathrm{Ga}\left[\mathrm{GaX}_{4}\right]$} Salts in Aromatic Hydrocarbons

In recent structural studies it could be demonstrated that $\mathrm{Ga}\left[\mathrm{GaX}_{4}\right]$ salts are taken up by aromatic solvents as $1: 1$ or $1: 2$ arene complexes $[1,5-10]$. These arene adducts can be crystallized as oligo-

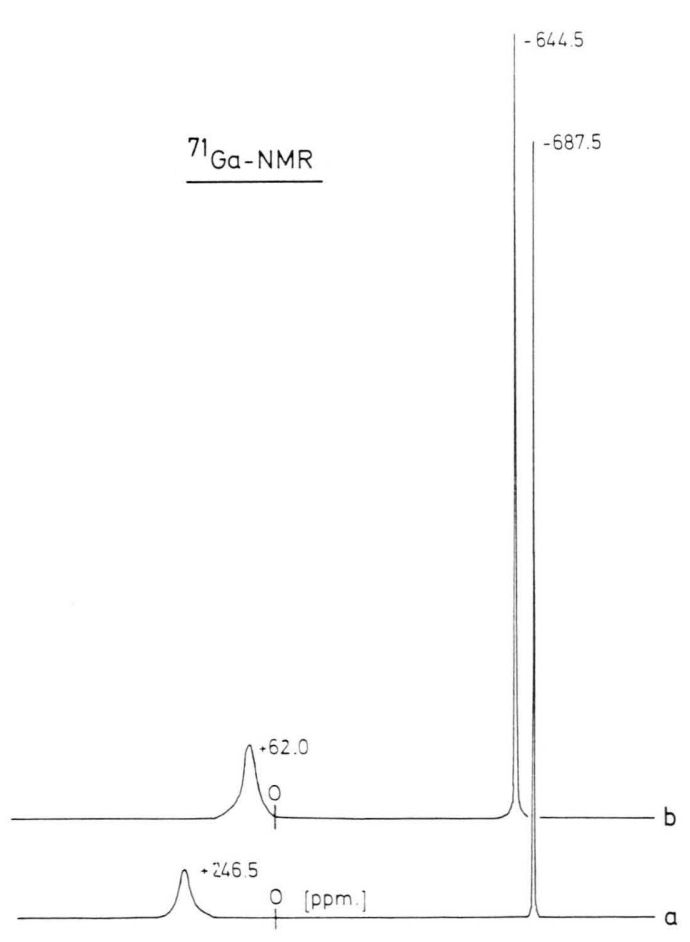

Fig. 4. ${ }^{71} \mathrm{Ga}$ NMR spectra of benzene solutions of $\mathrm{Ga}\left[\mathrm{GaCl}_{4}\right]$ (a) and $\mathrm{Ga}\left[\mathrm{GaBr}_{4}\right]$ (b) at $303 \mathrm{~K}$. Reference: $\mathrm{HNO}_{3}$-acidic aqueous $\mathrm{Ga}\left(\mathrm{NO}_{3}\right)_{3}$ solutions. $v=60.990 \mathrm{MHz}$. 
meric species, in which the $\mathrm{Ga}^{\mathrm{I}}$ center is hexahapto coordinated $\left(\eta^{6}\right)$ to the arene ring, i.e. perpendicularly above the rings. In the $1: 2$ complexes the two $\eta^{6}$-bonded rings form angles of $45-60^{\circ}$.

The high resolution ${ }^{71} \mathrm{Ga}$ NMR spectra of the solutions of these complexes in excess hydrocarbon are all characterized by a broad $\mathrm{GaCl}_{4}$ or $\mathrm{GaBr}_{4}$ resonance and a sharp (arene) ${ }_{n} \mathrm{Ga}^{\mathrm{I}}$ signal (Figure 4). The spectrum of a benzene solution of $\mathrm{Ga}\left[\mathrm{GaCl}_{4}\right]$ has been reported previously $[2,3]$. The drastic shift difference of the low-field signals obtained for chloride and bromide, together with a much smaller shift difference of the sharp-field signals, is again convincing evidence for the assignment to $\mathrm{Ga}^{\mathrm{III}}$ and $\mathrm{Ga}^{\mathrm{I}}$, respectively.

The chemical shifts of the gallium(I) resonances depend on the nature of the arene employed as a solvent. This effect is of course due to the direct arene-gallium(I) complexation. For mixtures of arenes, the gallium(I) shift observed corresponds to the value for the complex of the most electron-rich hydrocarbon (hexamethylbenzene $>$ mesitylene $>$ xylene $>$ toluene $>$ benzene). It is concluded that the metal ion is coordinated to the methyl-richer component.

Mono- or bis(arene) complexes cannot be distinguished by Ga NMR in solution at room temperature. There is rapid arene exchange of coordinated benzene and free benzene, and also between monoand bis-complex ions. Even cooling of toluene solutions below $-50^{\circ}$ gave no signal splitting. The

[1] For two recent summaries see: H. Schmidbaur, U. Thewalt, and T. Zafiropoulos, Organometallics 2, 1550 (1983); H. Schmidbaur, Angew. Chem. 97, 893 (1985).

[2] J. W. Akitt, N. N. Greenwood, and A. Storr, J. Chem. Soc. 1965, 4410 .

[3] J. W. Akitt, Annual Rep. NMR Spectr. 4 a, 466 (1972).

[4] A. S. Dworkin, L. L. Brown, A. C. Buchanan, and G. P. Smith, Tetrahedron Letters 1985, 2727.

[5] U. Thewalt, T. Zafiropoulos, and H. Schmidbaur, Z. Naturforsch. 39 b, 1642 (1984).

[6] H. Schmidbaur, U. Thewalt, and T. Zafiropoulos, Angew. Chem. 96, 60 (1984); Angew. Chem. Int. Ed. Engl. 23, 386 (1984).

[7] H. Schmidbaur, W. Bublak, J. Riede, and G. Müller, Angew. Chem. 97, 402 (1985); Angew. Chem. Int. Ed. Engl. 24, 414 (1985).
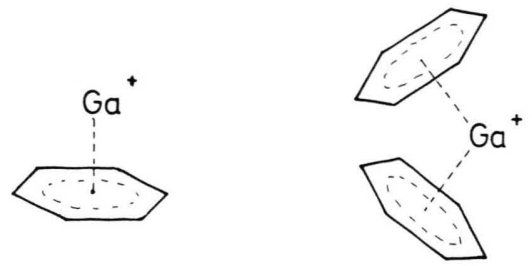

benzene exchange process therefore is associated with only very low energies of activation, probably lower than $9 \mathrm{kcal} / \mathrm{mole}$.

Separate signals are registered for mixtures of $\mathrm{Ga}_{2} \mathrm{Cl}_{4}$ and $\mathrm{Ga}_{2} \mathrm{Br}_{4}$ with arenes consisting of two liquid phases. As soon as the phase border disappears upon further dilution with excess solvent, the second signal is no longer visible.

The narrow lines of the gallium(I) resonances and their extreme high field shifts are indicative of a strong symmetrical shielding of the $\mathrm{Ga}^{\mathrm{I}}$ nuclei in the arene complexes. This effect is again attributed to the presence of the $4 \mathrm{~s}^{2}$ lone pair of electrons which provides a first "coordination sphere" of high shielding efficiency followed by the arene and halogen ligands at much larger distances.

\section{Acknowledgement}

Support of this work by Deutsche Forschungsgemeinschaft, Fonds der Chemischen Industrie, Preussag AG and Siemens AG is gratefully acknowledged.

[8] H. Schmidbaur, U. Thewalt, and T. Zafiropoulos, Chem. Ber. 117, 3381 (1984).

[9] J. Ebenhöch, G. Müller, J. Riede, and H. Schmidbaur, Angew. Chem. 96, 367 (1984); Angew. Chem. Int. Ed. Engl. 23, 386 (1984).

[10] G. Müller, W. Bublak, and H. Schmidbaur, Organometallics, in press.

[11] G. Garton and H. M. Powell, J. Inorg. Nucl. Chem. 4, 84 (1956)

[12] H. P. Beck, Z. Naturforsch. 39 b, 310 (1984).

[13] G. Gerlach, W. Hönle, and A. Simon, Z. Anorg. Allg. Chem. 486, 7 (1982).

[14] J. F. Baugher, P. C. Taylor, T. Oja, and P. J. Bray, J. Chem. Phys. 50, 4914 (1969). 